\title{
Multi-planar structures in the aftershock distribution of the Mid Niigata prefecture Earthquake in 2004
}

\author{
Shigeki Aoki ${ }^{1}$, Masaki Nishi ${ }^{2}$, Koji Nakamura $^{2}$, Tetsuo Hashimoto ${ }^{2}$, Sumio Yoshikawa $^{1 *}$, and Hidemi M. Ito ${ }^{2 \dagger}$ \\ ${ }^{1}$ Seismology and Volcanology Research Department, Meteorological Research Institute, \\ Nagamine 1-1, Tsukuba, Ibaraki 305-0052, Japan \\ ${ }^{2}$ Seismological and Volcanological Department, Japan Meteorological Agency, Otemachi 1-3-4, Chiyoda, Tokyo 100-8122, Japan
}

(Received February 16, 2005; Revised April 11, 2005; Accepted April 15, 2005)

\begin{abstract}
A shallow destructive inland earthquake of M6.8 occurred on Oct. 23, 2004 (JST) in the middle part of Niigata prefecture, Japan. The aftershock activity was high as compared to those of the other shallow inland earthquakes in Japan. We relocated the sources of the main shock and aftershock activity by adopting the double-difference earthquake location algorithm. The precisely relocated hypocenter distribution shows that there are a doubleplanar structure with a distance $5 \mathrm{~km}$ in parallel dipping in WNW with about 50 degrees and a single-planar structure dipping in ESE with about 15 degrees. The upper and lower planes of the double plane began to be formed with the main shock and the largest aftershock of M6.5, respectively, while the ESE dipping plane began to be formed with the 3rd largest aftershock of M6.1. The three planes represent the fault planes of the large events mentioned above. The aftershock distribution is found to be a superposition of the fault planes of the main shock and the large aftershocks. The high aftershock activity is attributed to the formation of the fault planes.
\end{abstract}

Key words: The Mid Niigata prefecture Earthquake in 2004, aftershock distribution, double-planed seismic zone, fault plane, double-difference earthquake location algorithm.

\section{Introduction}

A shallow destructive inland earthquake of M6.8 occurred at 17:56 on Oct. 23, 2004 (JST) in the middle part of Niigata prefecture, Japan (hereafter referred to as the Mid Niigata prefecture Earthquake in 2004). Seismic intensity 7 , the largest value in the seismic intensity scale of the Japan Meteorological Agency (JMA), was recorded at Kawaguchi town in Niigata prefecture. The focal mechanism of this earthquake was of a reverse fault type with a compression axis in the WNW-ESE direction. This earthquake was the largest in the shallow inland earthquakes of reverse fault type in Japan since Oct. 1997, when JMA began to compile all the seismic waveform data in Japan and make a catalog of seismological data in Japan (hereafter referred to as the integrated seismological catalog) in cooperation with the National University Corporations and the National Research Institute for Earth Science and Disaster Prevention (NIED).

The Mid Niigata prefecture Earthquake in 2004 accompanied the prominent aftershock activity with four aftershocks of M6.0 or greater: the largest aftershock of M6.5

*Present address; Seismological and Volcanological Department, Japan Meteorological Agency, Otemachi 1-3-4, Chiyoda, Tokyo 100-8122, Japan.

$\dagger$ Present address; Seismology and Volcanology Research Department, Meteorological Research Institute, Nagamine 1-1, Tsukuba, Ibaraki 3050052, Japan.

Copy right(c) The Society of Geomagnetism and Earth, Planetary and Space Sciences (SGEPSS); The Seismological Society of Japan; The Volcanological Society of Japan; The Geodetic Society of Japan; The Japanese Society for Planetary Sciences; TERRAPUB occurred at 18:34 on Oct. 23, the 2nd largest of M6.3 at 18:03 on Oct. 23, the 3rd largest of M6.1 at 10:40 on Oct. 27 , and the 4th largest of M6.0 at 18:11 on Oct. 23. As shown later, the cumulative number of aftershocks was numerous as compared to those of the other shallow inland earthquakes in Japan. The difference 0.3 in magnitude between the main shock and the largest aftershock was smaller than the median 1.6 for main shocks of M6.8 (Utsu, 2002). It suggests that this sequence is not a simple mainshockaftershock sequence. Figure 1 shows a spatial distribution of main shock and aftershocks. The hypocenters of main shock and aftershocks are distributed in the NNE-SSW direction extending about $35 \mathrm{~km}$ in horizontal width and from 0 to $20 \mathrm{~km}$ in depth. The aftershock area is located in the high strain rate zone in the eastern margin of the Japan Sea, which was found based on the geological data (Okamura, 2002) and on the data of the dense GPS array (Sagiya et al., 2000).

The main purpose of this study is to understand the reason of the high aftershock activity of the Mid Niigata prefecture Earthquake in 2004 in relation with its aftershock distribution. We determine precise hypocenter locations of events by adopting the double-difference earthquake location algorithm (Waldhauser and Ellsworth, 2000; hereafter referred to as the DD method), and investigate the structure of aftershock distribution in detail.

\section{Method and Data}

In the DD method, we use a double difference which is defined as a residual between observed and calculated travel time differences between two events at a common 


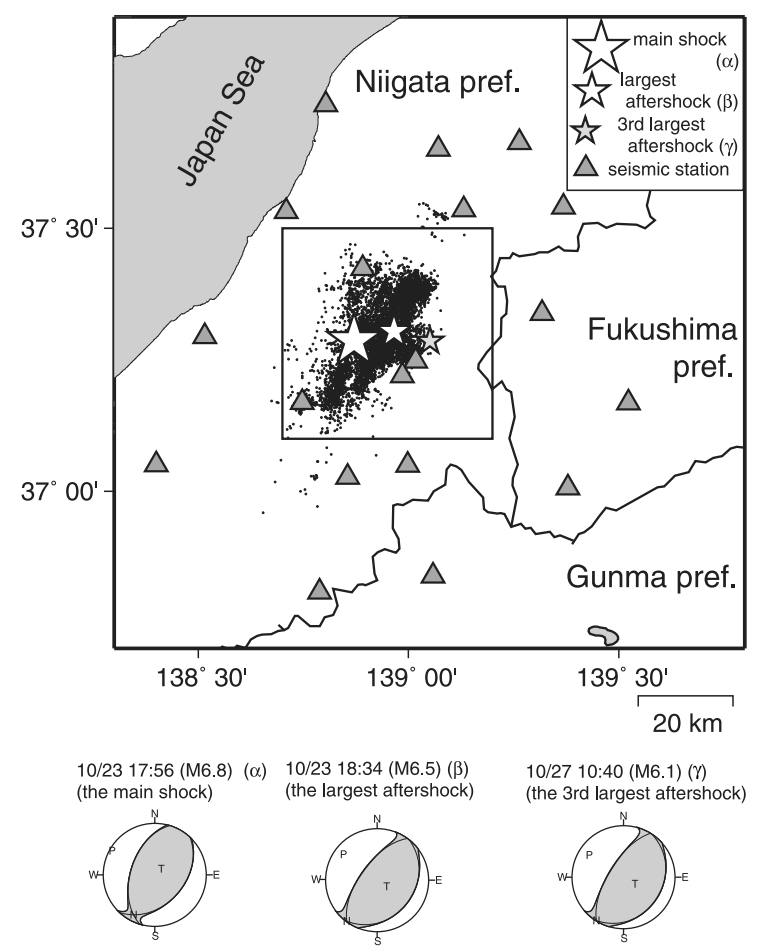

Fig. 1. Distributions of the Mid Niigata prefecture Earthquake in 2004, the aftershocks and seismic stations used in this study. Big, small white and small gray stars denote epicenters of the main shock $(\alpha)$, the largest aftershock of M6.5 $(\beta)$, the 3rd largest aftershock of M6.1 $(\gamma)$, respectively. Gray triangles indicate 19 seismic stations. Three CMT solutions below the map show the focal mechanisms of the large events mentioned above. Square indicates the area shown in Fig. 2.

station. If the hypocentral distance between two events is small enough as compared to the events-station distance, we can cancel errors due to unrealistic seismic velocity models (e.g., 1D velocity model) and estimate the relative locations of two events with a high resolution.

For our original data set we analyze the events for the period from the occurrence time 17:56 on Oct. 23 of the main shock to 24:00 Nov. 30, 2004 in the integrated seismological catalog. We, at first, correct the hypocenters and their $P$ - and $S$-wave arrival times of the original data set by the following procedure, and then apply the DD method to the corrected data set.

(1) We select the $P$ - and $S$-wave arrival times observed at 19 regional permanent seismic stations managed by NIED, University of Tokyo and JMA, whose mutual distances are less than $70 \mathrm{~km}$ (Fig. 1), and determine hypocenters by the JMA routine algorithm (Ueno et al., 2002). The initial number of events located is 6752 .

(2) At each station, we make a station correction in terms of an average residual between observed and calculated travel times, and relocate again the hypocenters. Then, we use the relocated hypocenters and the corrected arrival times as the final input data set for the DD method.

(3) We obtain the final hypocenters relocated by applying the DD method, which are used in the following sections. The number of events finally relocated is 6409. About 350 events were deleted, because they were relocated above the ground during an iteration process or because they lost the linkage in the process of calculation of the double difference.

For the calculation of travel times in all the location algorithms in this study, we use the velocity model developed by Ueno et al. (2002) for JMA routine hypocenter determination.

Figure 2 shows distributions of the hypocenters relocated in this study. The dotted line A-B drawn in Fig. 2(a), in $\mathrm{N} 62^{\circ} \mathrm{W}$, is an average direction of the normal vectors of the WNW dipping nodal planes inferred from three JMA CMT solutions in Fig. 1. The solutions were determined by the method developed by Nakamura et al. (2003). The relocated hypocenters do not shift systematically, but tend to concentrate on the planes or clusters as compared to those of the original data set.

The distribution of aftershocks relocated in this study systematically deviates by about $4 \mathrm{~km}$ in ESE direction and is hazy in shallower parts as compared to that of the aftershocks located by a dense temporary seismic network (e.g., Sakai et al., 2005). Systematic errors in initial locations sometimes cause systematic errors in absolute locations of hypocenters relocated in the DD method (Waldhauser and Ellsworth, 2000), but this does not harm the discussion in the following sections which is primarily concerned with relative locations of aftershocks.

\section{Aftershock Activity \\ 3.1 Overview}

We can see several planes or clusters formed by aftershocks in Fig. 2. In particular, the WNW dipping double plane with about 50 degrees, hereafter referred to as the upper and lower planes, is remarkable. Also notable is the ESE dipping single plane with about 15 degrees which connects to an upper edge of the lower plane.

We divide the period from the occurrence time of the main shock until 24:00 Nov. 30 into four stages by using four events: the main shock $(\alpha)$, the largest aftershock $(\beta)$ on Oct. 23, the 3rd largest aftershock $(\gamma)$ on Oct. 27 , and the aftershock of M5.9 $(\delta)$ at 11:15 on Nov. 8. Each stage begins with one of the events and ends just before the next event. For example, the 1st is from 17:56 to 18:34 on Oct. 23. Figure 3 shows a distribution of the hypocenters of earthquakes which occurred in each stage. Figure 4 shows temporal changes of cumulative numbers of aftershocks of the whole region, each cluster of this sequence and the other shallow inland earthquakes in Japan. The aftershock activity of the whole region is significantly high as compared to the other inland earthquakes.

\subsection{The upper plane of the double-planed seismic zone}

The main shock $(\alpha)$ occurred on the upper plane. Hypocenters forming this plane are distributed in the NNESSW direction extending about $35 \mathrm{~km}$ in horizontal width. The magnitude $M_{a f t}=6.7$ is expected from the relation between the magnitude of the main shock and the length of the aftershock zone (Utsu, 2002). $M_{a f t}$ of this plane nearly corresponds to the actual magnitude of the main shock $(\alpha)$. The northeastern and the central parts of this plane bend at a depth range from 8 to $10 \mathrm{~km}$ as shown in Figs. 2(c) and (d). The deeper part of this plane below the bending depth dips with an angle of about 55 degrees. The shallower part 

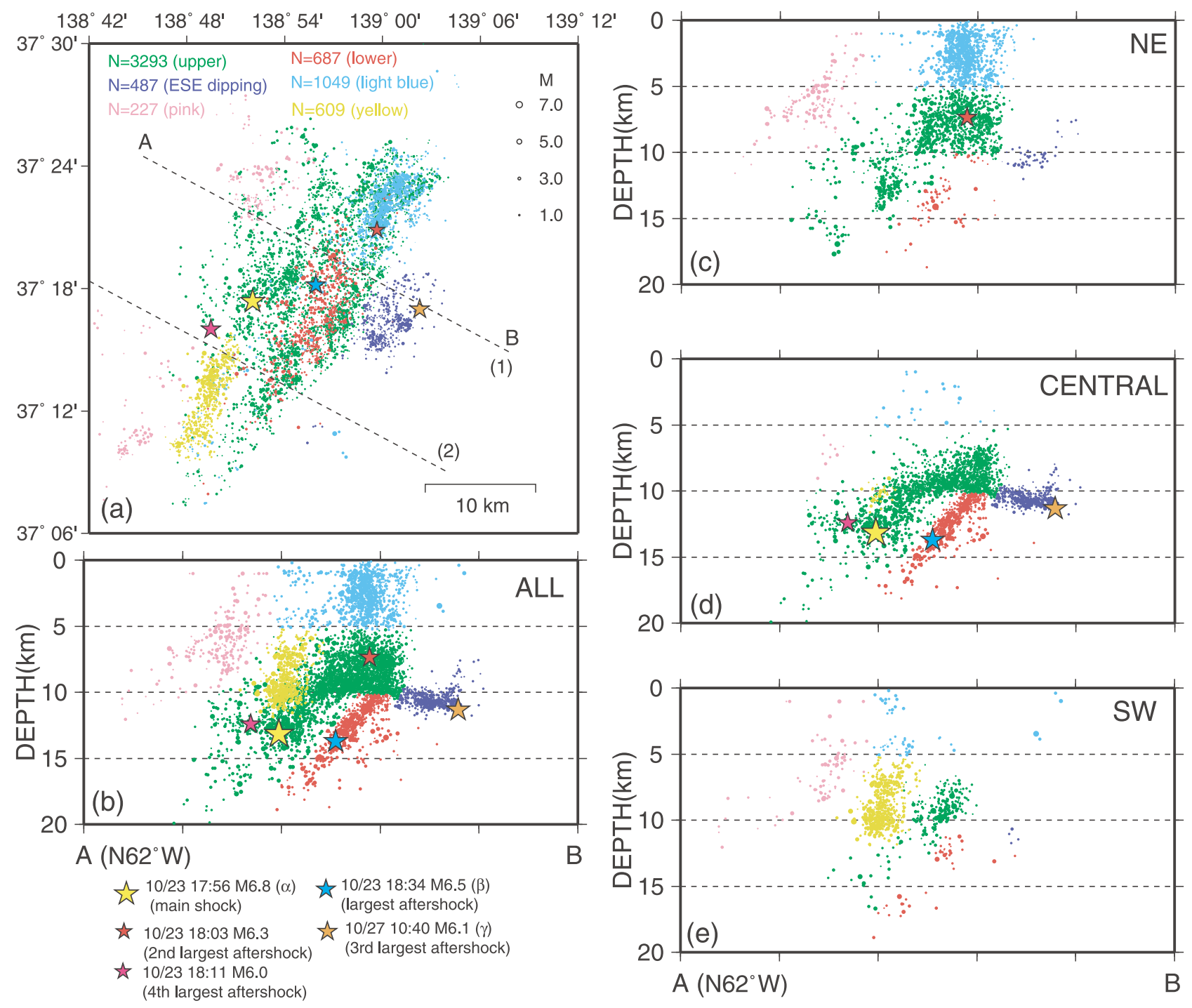

Fig. 2. Distribution of relocated hypocenters by the DD method. The events which occurred from 17:56 Oct. 23 to 24:00 Nov. 30 , 2004 are shown. Green, red, blue, light blue, pink and yellow circles denote hypocenters of the upper plane, the lower plane, the ESE dipping plane, the light blue cluster, the pink clusters and the yellow cluster, respectively. (a) Map viewing of hypocenter distribution. (b)-(e) Vertical cross sections along A-B for all the events, for events located in the northeastern side of the dotted line (1), for events located between two dotted lines, and for events located in the southwestern side of the dotted line (2). The ratio of the scales of the map viewing (a) and the vertical cross sections (b)-(e) is 1:1.2.

dips with an angle of about 15 degrees. In the southwestern part of the aftershock zone (Fig. 2(e)), activity of the deeper part is weak.

As Figs. 3(a) and (e) indicate, this plane began to be formed immediately after the main shock $(\alpha)$, and its activity decreased following the modified Omori formula (Utsu, 2002) with the $p$ value $=1.21$ for aftershocks with M2.0 or greater. Seismicity of this plane was most active among all the clusters as shown in Fig. 4. We cannot identify the beginnings of formation of the shallower and deeper parts of this plane.

From the above investigation, we see that the activity of the upper plane indicates the aftershock activity of the main shock $(\alpha)$ and that the upper plane, at least its deeper part, represents the fault plane of the main shock $(\alpha)$. The deeper part approximately corresponds to the WNW dipping nodal plane of the CMT solution of the main shock $(\alpha)$ (Fig. 1). The source process of the main shock $(\alpha)$ (Meteorological Research Institute, 2004) indicates that there was a large amount of slip in the deeper part of the fault plane. This suggests that the rupture was weakened at the bending depth of the upper plane.

As it is shown in Fig. 2, variation in depth of the upper plane is larger than those of the lower and the ESE dipping planes. This suggests that the large aftershock in the upper plane accompanied secondary aftershocks, which are distributed on a plane whose geometry is somewhat different from that of the upper plane. Actually, the 2nd and the 4th largest aftershocks of M6.3 and M6.0 occurred in the upper plane, while no M6.0 or greater events occurred in the lower and the ESE dipping planes, except the largest $(\beta)$ and the 3rd largest aftershocks $(\gamma)$. The shallower part of the upper plane seems to be thickened due to a mixture of the plane with a dip of about 15 degrees (the shallower part itself), the extensions of the lower and the ESE dipping planes, and other clusters. In other words, we cannot discriminate each cluster above mentioned from the whole of the shallower part. In fact the Disaster Prevention Research 

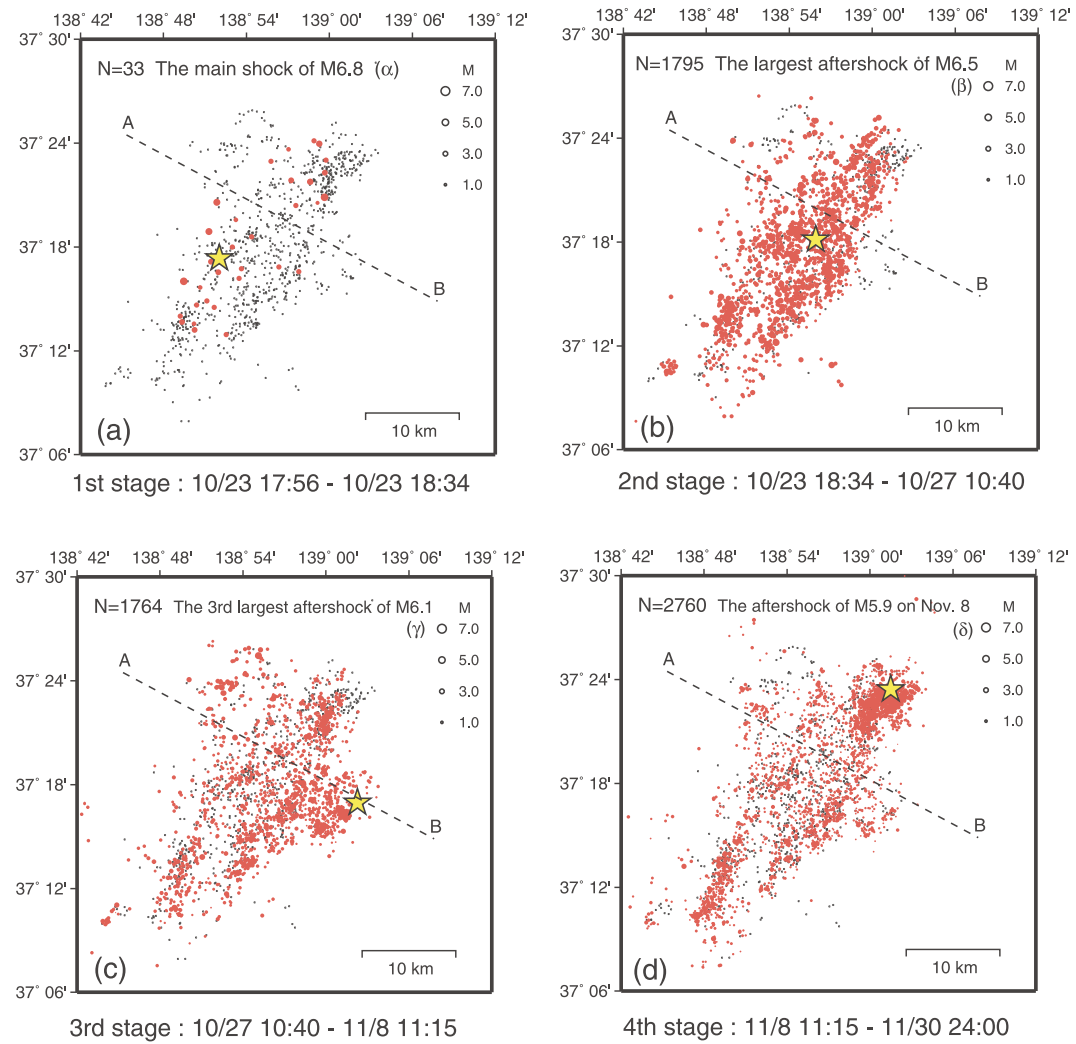
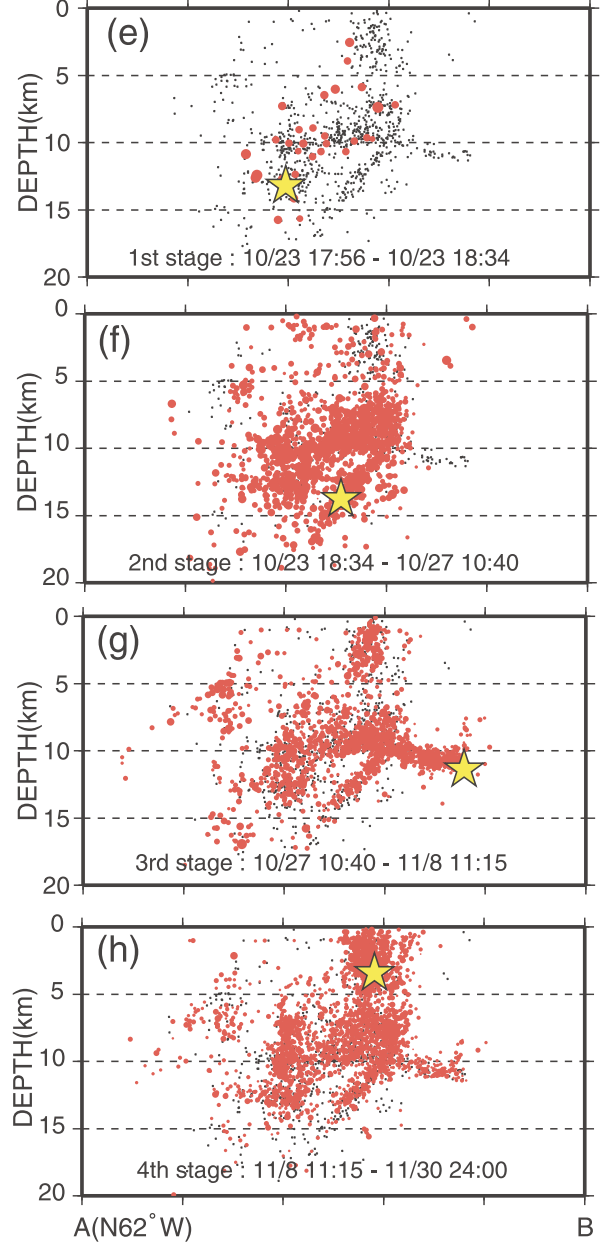

Fig. 3. Distribution of the hypocenters of earthquakes which occurred in each stage. The entire period is divided into four stages by using four events: the main shock $(\alpha)$, the largest aftershock $(\beta)$, the 3rd largest aftershocks $(\gamma)$, and the aftershock $(\delta)$ of M5.9 on Nov. 8 . Each stage begins with one of the events and ends just before the next event. Red circles indicate the events occurred in the stage. A star denotes the first event occurred in the stage. M2.5 or greater events for the entire period are shown by black points in each figure for the guide of the planar structures. The ratio of the scales of the map viewings (a)-(d) and the vertical cross sections (e)-(h) is 1:1.44.

Institute of Kyoto University and Institute of Seismology and Volcanology of Kyushu University (2004) found other planar structures in the aftershock distribution relocated by temporary seismic stations. A cluster in the shallower part of the upper plane found in the southwestern part of aftershock area (Fig. 3(e)) may be associated with the 2nd largest aftershock which is located in the northeastward extension of this cluster.

\subsection{The lower plane of the double-planed seismic zone}

The largest aftershock $(\beta)$ is located on the lower plane. Hypocenters forming this plane are distributed in the NNESSW direction extending about $25 \mathrm{~km}$ horizontally $\left(M_{\text {aft }}=\right.$ 6.4 ), and on the WNW dipping plane with an angle of about 50 degrees. $M_{a f t}$ of this plane almost corresponds to the actual magnitude of the aftershock $(\beta)$. This plane is nearly parallel to the deeper part of the upper plane and the spacing of these planes is about $5 \mathrm{~km}$. As Fig. 3 clearly indicates, no event is located on this plane before the largest aftershock $(\beta)$; in other words, this plane began to be formed immediately after the aftershock $(\beta)$. The beginnings of the formation of the upper and lower planes can be discriminated only in the precise hypocenters relocated by the permanent stations used in this study, because the time from the main shock $(\alpha)$ to the aftershock $(\beta)$ was just 38 minutes. Activity quickly decreased after the aftershock $(\beta)$ with the $p$ value, 1.37, as shown in Fig. 4.

From the above investigation, we see that the activity of the lower plane indicates the secondary aftershock activity of the largest aftershock $(\beta)$ and that the lower plane represents the fault plane of the aftershock $(\beta)$. The lower plane approximately corresponds to the WNW dipping nodal plane of the CMT solution of the aftershock $(\beta)$ (Fig. 1). The aftershock $(\beta)$ occurred off the fault plane of the main shock $(\alpha)$ and formed a different fault plane.

\subsection{The ESE dipping plane}

The 3rd largest aftershock $(\gamma)$ occurred on the ESE dipping plane. Hypocenters forming this plane are distributed in the NNE-SSW direction extending about $10 \mathrm{~km}$ horizontally $\left(M_{a f t}=5.6\right)$. As Fig. 3 indicates, this plane began to be formed immediately after the 3rd largest aftershock $(\gamma)$ initiating the 3rd stage (Figs. 3(c) and (g)). Activity decreased after the aftershock $(\gamma)$ with the $p$ value, 1.13 . Seismicity of this plane was lower than that of the double plane as shown in Fig. 4.

From the above investigation, we see that the activity of the ESE dipping plane indicates the secondary aftershock 


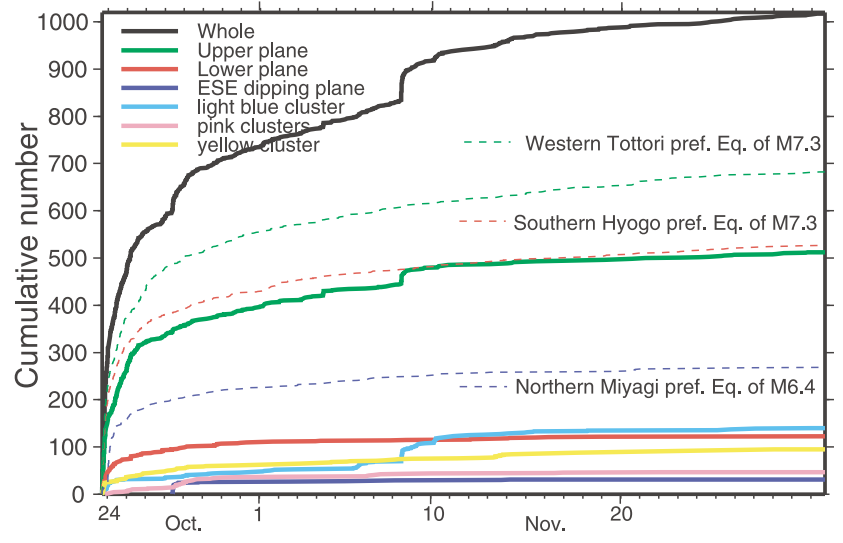

Fig. 4. Temporal change of cumulative number of the M2.5 or greater events. Green, red, blue, light blue, pink and yellow thick lines denote the upper plane, the lower plane, the ESE dipping plane, the light blue cluster, the pink clusters and the yellow cluster, respectively. Black line denotes the whole region. Green, red and blue thin dotted lines denote the events of the 2000 Western Tottori prefecture Earthquake of M7.3, the 1995 Southern Hyogo prefecture Earthquake of M7.3 and the 2003 Northern Miyagi prefecture Earthquake of M6.4, respectively. Start times for the other inland earthquakes are synchronized the occurrence time of the Mid Niigata prefecture Earthquake.

activity of the 3rd largest aftershock $(\gamma)$ and that the ESE dipping plane represents the fault plane of the aftershock $(\gamma)$. The ESE dipping plane corresponds nearly to the ESE dipping nodal plane of the CMT solution of the aftershock $(\gamma)$ (Fig. 1). The aftershock $(\gamma)$ occurred off the fault planes of the main shock $(\alpha)$ and the largest aftershock $(\beta)$ and formed a different fault plane. The fault of the aftershock $(\gamma)$ is a conjugate to those of $(\alpha)$ and $(\beta)$.

$M_{a f t}$ of this plane is somewhat smaller than the actual magnitude of the aftershock $(\gamma)$, which suggests a stress drop of this event is high as compared to that of the earthquake having the same seismic moment. Based on an analysis of the source processes, Yamanaka (2004) obtained the stress drop $15 \mathrm{MPa}$ for the aftershock $(\gamma)$, higher than 8.5 $\mathrm{MPa}$ for the main shock $(\alpha)$, and than $11 \mathrm{MPa}$ for the largest aftershock $(\beta)$.

\subsection{Other activities}

In Fig. 2(b), in addition to the three planes mentioned above, there are three clusters colored light blue, pink and yellow. In this section, we explain their activities briefly.

Light blue cluster is located in the northeastern part of the whole aftershock zone with focal depths from 0 to $5 \mathrm{~km}$. This cluster seems to be located in a shallower extension of the upper plane. However, temporal variation of its activity is different from that on the upper plane. The largest event in this cluster is the aftershock of M5.9 $(\delta)$ on Nov. 8. As Fig. 4 indicates, seismicity, at first, was weak during the period from the main shock $(\alpha)$ to just before the aftershock $(\delta)$. After the aftershock $(\delta)$, this cluster was swiftly activated and the cumulative number of events finally became the second most in number. The activity of this cluster is of a swarm type as a whole.

Pink clusters are located in the northeastern and the southwestern parts of the aftershock zone, in the WNW side of the double plane at a depth range from 0 to $10 \mathrm{~km}$. They have no M5.5 or greater event. They are distributed around
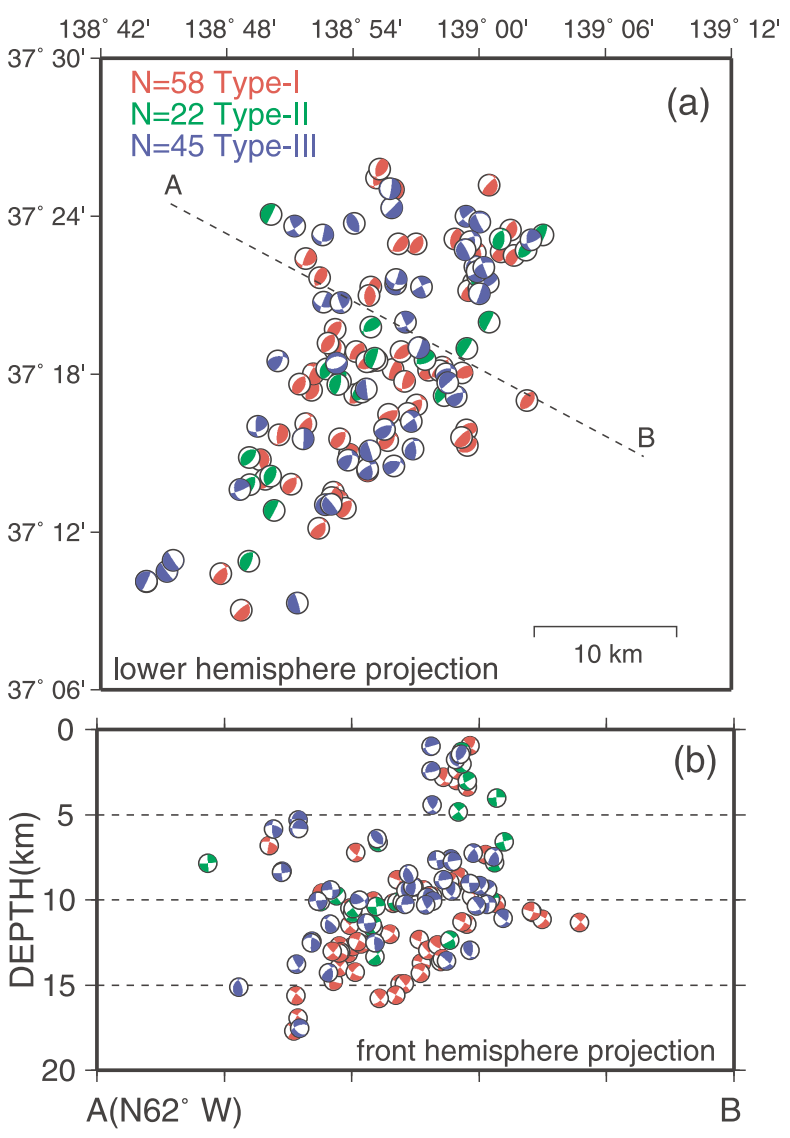

Fig. 5. Distribution of the fault plane solutions estimated from initial motions. Type-I, Type-II and Type-III solutions are shown by red, green and blue beach balls, respectively. The hypocenters of beach balls are replaced with the relocated hypocenters by the DD method for plotting. The ratio of the scales of the map viewing (a) and the vertical cross section (b) is $1: 1.2$.

a plane parallel to the upper plane as shown in Figs. 2(c) and 2(e). Horizontal distribution is restricted within a small area and seismicity was weak during the entire period, as indicated in Fig. 4.

Yellow cluster is located in the southwestern part of the aftershock zone, in the WNW side of the shallower part of the upper plane at a depth range from 5 to $12 \mathrm{~km}$. It has no M5.5 or greater event, but the 4th largest aftershock of M6.0 is located near this cluster. Activity monotonously decreased after the main shock $(\alpha)$.

It will be interesting to discuss these clusters from a viewpoint of triggered seismicity, which is left to future studies.

\section{Comparison with the Fault Plane Solutions}

Figure 5 shows a distribution of the fault plane solutions estimated from initial motions which are determined by JMA routine algorithm (Nakamura and Mochizuki, 1988). Most of them are of reverse fault type with the same nodal plane as the main shock $(\alpha)$. On the other hand, there are some solutions of other fault types. According to fault type, we divide them into three groups: (1) Type-I-reverse fault type with a WNW dipping nodal plane with about 40 degrees or greater; (2) Type-II-reverse fault type with a WNW dipping nodal plane with about 40 degrees or less; 
and (3) Type-III-other fault types. The main shock $(\alpha)$, the largest aftershock $(\beta)$ and the aftershock $(\gamma)$ belong to Type-I. Here reverse fault type with WNW dipping nodal plane is defined by a condition on the strike $\varphi$ and the rake $\lambda: 163^{\circ} \leq \varphi \leq 253^{\circ}$, and $45^{\circ} \leq \lambda \leq 135^{\circ}$.

In the deeper part of the upper plane (Fig. 5(b)), Type-I solutions are distributed dominantly on this plane. Most of the Type-III are distributed off this plane. In the shallower part of the upper plane, the distribution is complex, but it is interesting that some of the Type-II are distributed along this plane with a dip of about 15 degrees. In the lower plane and the ESE dipping plane, most of the solutions are of Type-I. The dips of two nodal planes of Type-I are in agreement with the dips of these planes. No characteristic is identified in the light blue, pink and yellow clusters.

Though the distribution of the fault plane solutions of the aftershocks is extremely complex, the agreement of the fault plane structures with the focal mechanisms seems to indicate that there exists a close relationship between the redistributed stress by formation of complicated fault structures and the occurrence of aftershocks. There are many aftershocks having the same focal mechanisms as the main shock $(\alpha)$ on the fault planes of the main shock $(\alpha)$, the largest $(\beta)$ and the 3rd largest aftershocks $(\gamma)$. However, the aftershocks having different focal mechanisms seem to occur off these fault planes.

\section{Summary}

We precisely relocated the Mid Niigata prefecture Earthquake in 2004 and the aftershocks by the DD method. We can summarize characteristics of this activity as follows: (1) the distribution of the hypocenters has a double-planar structure in parallel dipping in WNW and a single-planar structure dipping in ESE, (2) the upper and lower planes of the double plane began to be formed with the main shock $(\alpha)$ and the largest aftershock $(\beta)$, and finally the ESE dipping plane began to be formed with the 3rd largest aftershock $(\gamma)$, and (3) the areas of the planes are almost proportional to the magnitudes of these events. From the above characteristics we can conclude that the three dipping planes formed by the aftershocks represent the fault planes of the large events mentioned above. The fault of the $3 \mathrm{rd}$ largest aftershock $(\gamma)$ is a conjugate to those of $(\alpha)$ and $(\beta)$. The comparison of the focal mechanisms of the aftershocks with the fault plane structures suggests that there exists a close relationship between the re-distributed stress by formation of complicated fault structures and the occurrence of aftershocks.

The sequence of aftershock activity forming each fault plane is very simple and cumulative number of each activity is comparable to the one expected in the aftershock activity of the shallow inland earthquake having the same magnitude. We can interpret the complicated aftershock distribution with high activity of this earthquake as a superposition of normal aftershock activity of the main shock and nor- mal secondary aftershock activities of the other subsequent large aftershocks.

Acknowledgments. The integrated seismological catalog was made by JMA and the Ministry of Education, Culture, Sports, Science and Technology in Japan. The hypocenters were determined by the data of NIED, University of Tokyo and JMA. We are very grateful to members of the above organizations. We thank Y. Yoshida for many valuable discussions about our preliminary results presented at the 160th meeting of the CCEP (Nov. 4, 2004) and S. Sakai for sending a preprint of their paper. Comments by N. Hirata, Y. Okada and R. Hino were very helpful in improving the original manuscript. We used the 'hypoDD' program (Waldhauser, 2001) for applying the DD method and the 'hypdsp' program (Yokoyama, 1997) for a seismicity analysis. Figures were drawn by using GMT (Wessel and Smith, 1991).

\section{References}

Disaster Prevention Research Institute of Kyoto University and Institute of Seismology and Volcanology of Kyushu University, The fault planes estimated from the aftershock distribution, http://cais.gsi.go.jp/YOCHIREN/JIS/161/image161/009.pdf, Abstract of the 161st meeting of CCEP, 2004 (in Japanese).

Meteorological Research Institute, Source process of the main shock and largest aftershock of 2004 Niigata, Chuetsu earthquake, http://cais.gsi.go.jp/YOCHIREN/JIS/160/image160/008.pdf, Abstract of the 160th meeting of CCEP, 2004 (in Japanese).

Nakamura, K., S. Aoki, and Y. Yoshida, Centroid moment tensor analysis by using the JMA broadband seismic observation network, Q. J. Seismol., 66, 1-15, 2003 (in Japanese with English abstract).

Nakamura, M. and E. Mochizuki, Focal mechanism solutions and their reliability determined p-wave first motions, Q. J. Seismol., 52, 1-14, 1988 (in Japanese with English abstract).

Okamura, Y., The geological high strain rate zone after the Neogene, in Active Faults and Seismo-Tectonics of the Eastern Margin of the Japan Sea, edited by M. Ohtake, A. Taira, and Y. Ota, pp. 111-121, University of Tokyo Press, 2002 (in Japanese).

Sagiya, T., S. Miyazaki, and T. Tada, Continuous GPS array and presentday crustal deformation of Japan, PAGEOPH, 157, 2303-2322, 2000.

Sakai, S., N. Hirata, A. Kato, E. Kurashimo, T. Iwasaki, and T. Kanazawa, Multi-fault system of the 2004 Mid-Niigata Prefecture Earthquake and its aftershocks, Earth Planets Space, 57, this issue, 417-422, 2005.

Ueno, H., S. Hatakeyama, T. Aketagawa, J. Funasaki, and N. Hamada, Improvement of hypocenter determination procedure in the Japan Meteorological Agency, Q. J. Seismol., 65, 123-134, 2002 (in Japanese with English abstract).

Utsu, T., Statistical features of seismicity, in International Handbook of Earthquake and Engineering Seismology, Part A, edited by W. H. K. Lee, H. Kanamori, P. C. Jennings, and C. Kisslinger, pp. 719-732, Academic Press, 2002.

Waldhauser, F., HypoDD - A program to compute double-difference hypocenter locations, U.S.G.S. Open File Report, 01-113, 25 pp., 2001.

Waldhauser, F. and W. L. Ellsworth, A double-difference earthquake location algorithm: Method and application to the Northern Hayward fault, California, Bull. Seismol. Soc. Am., 90, 1353-1368, 2000.

Wessel, P. and W. H. F. Smith, Free software helps map and display data, EOS Trans. Am. Geophys. Union, 72, 445-446, 1991.

Yamanaka, Y., The earthquakes occurred in the mid Niigata prefecture on Oct., 2004, http://www.eri.u-tokyo.ac.jp/sanchu/Seismo_Note/ 2004/EIC154a.html, EIC Seismological Note, 154+, 2004 (in Japanese).

Yokoyama, H., A program for seismic data analysis using the $\mathrm{X}$ window system, Q. J. Seismol., 60, 37-51, 1997 (in Japanese).

S. Aoki (e-mail: shigaoki@mri-jma.go.jp), M. Nishi, K. Nakamura, T. Hashimoto, S. Yoshikawa, and H. M. Ito 